\title{
SPREADING OF BRINE DISCHARGED INTO THE PUCK BAY (SOUTH BALTIC SEA): THEORETICAL STUDY VERSUS FIELD OBSERVATIONS
}

\section{Malgorzata Robakiewicz}

\section{Institute of Hydro-Engineering of the Polish Academy of Sciences 80-328 Gdańsk, ul. Kościerska 7; www. Ibwpan.gda.pl}

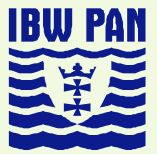

General information
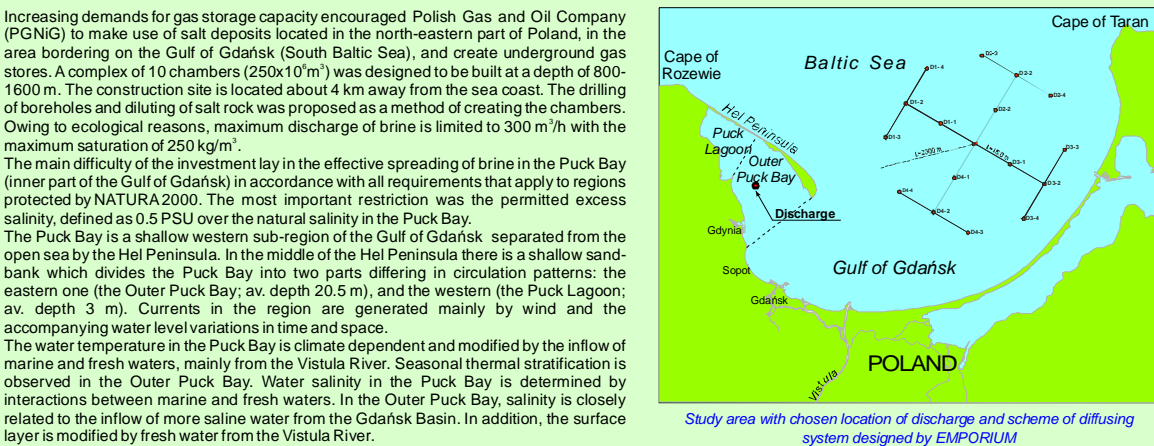

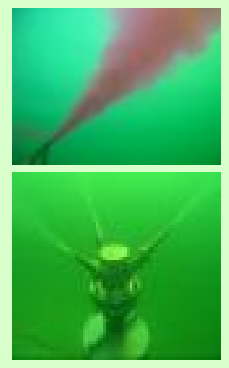

Working diffuser

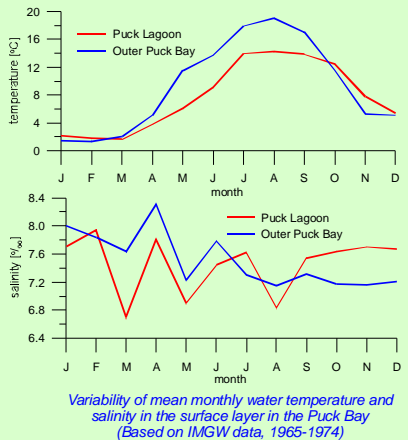

Pre-investment analysis of brine discharge, modeling approach modeling approach

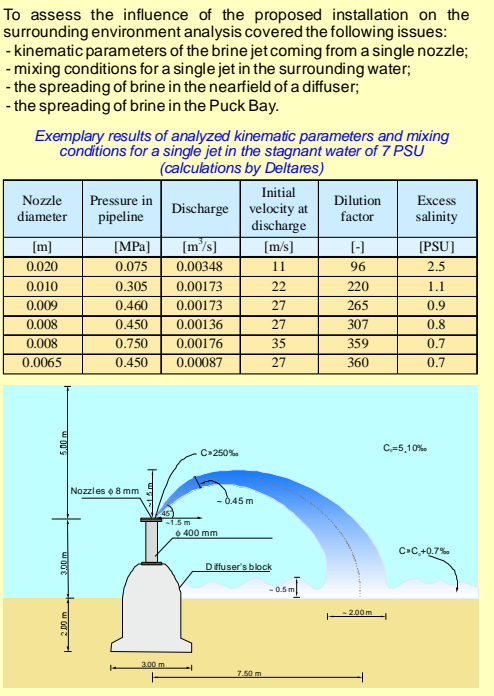

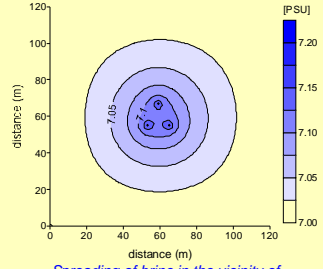
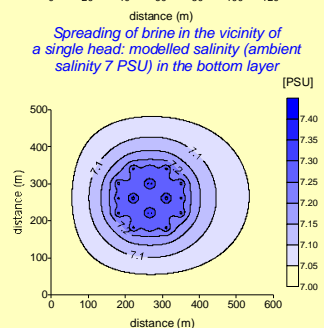

Spreading of brine in the vicinity of the system
of heads (ambientsalinity 7 PSU)

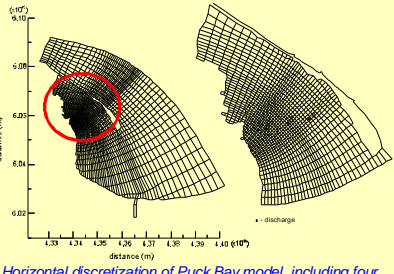

Horizontal discretizaztion of Puck Bay model, including four
optional locations analysed (based on Delft3D FLOW)

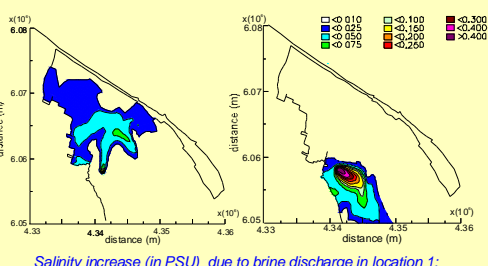

Salinity increase (in PSU) due to brine discharge in location 1:
25.02 .1997 (left). 7.07.2006 (right)
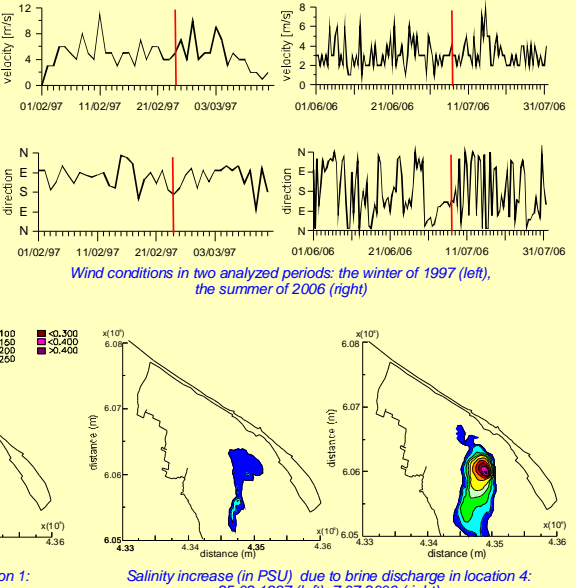

CONCLUSIONS: Based on theoretical analysis it was decided to bu
locate the center of the installation 2300 m off shore

Monitoring in the near-field of installation
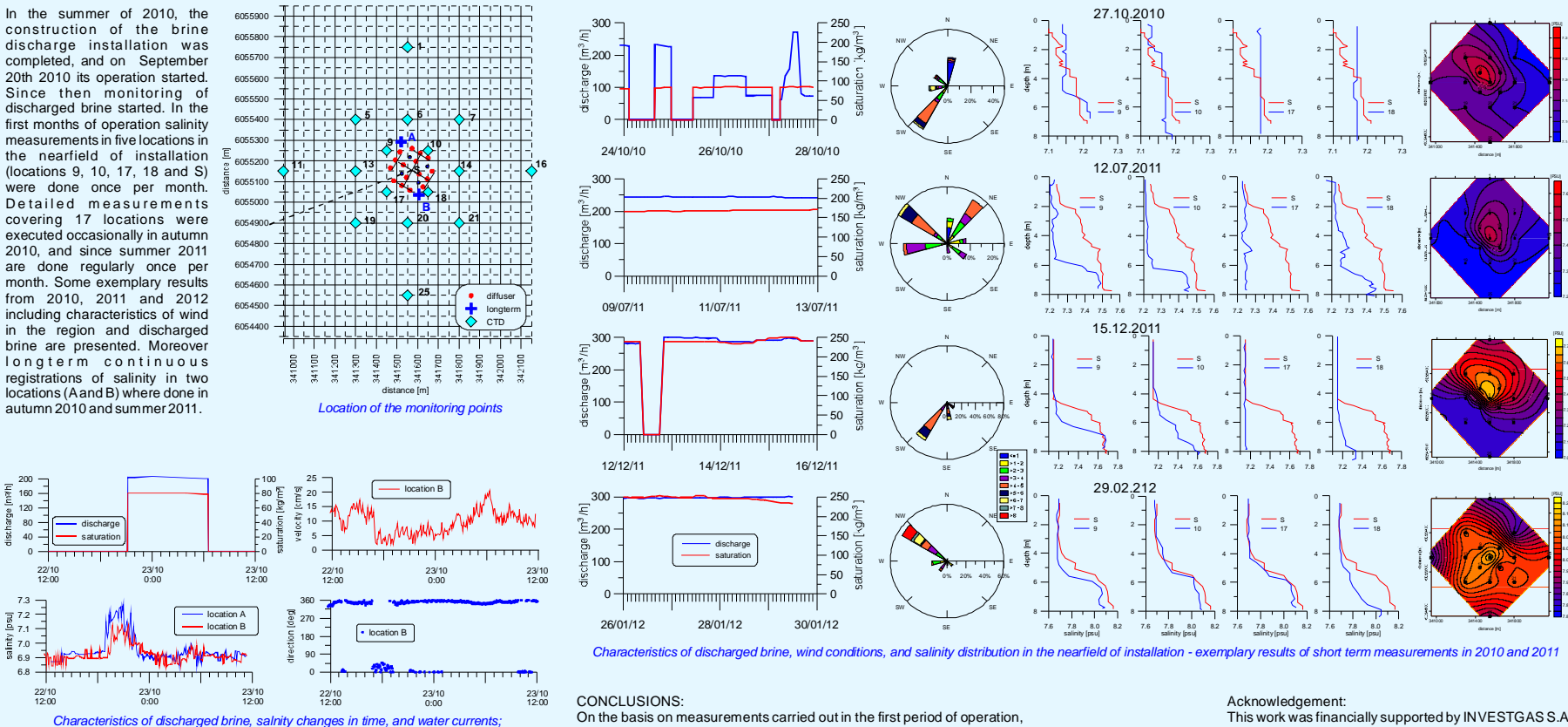

CONCLUSIONS:

On the basis on measurements carried out in the first period of operation,
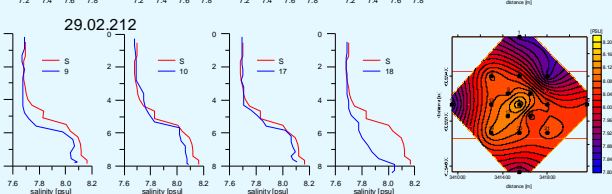